\title{
ПРАВОВАЯ ПРИРОДА ПУБЛИЧНОГО РАЗМЕЩЕНИЯ АКЦИЙ
}

\begin{abstract}
Аннотация: в настоящей статье поднимается одна из не до конца разрешенных проблем в теории права: определение правовой природы публичного размещения акций. Для разрешения данной проблемы автором исследуются четыре основные теории правовой природы публичного размещения акций: теория договора инвестирования, теория односторонней распорядительной сделки, теория двусторонней распорядительной сделки и теория договора купли-продажи, и дается оценка каждой из вышеперечисленных теорий. В рамках рассмотрения вышеперечисленных теорий автор приходит квыводу о том, что теории односторонней распорядительной сделки и двусторонней распорядительной сделки не являются состоятельными и не могут быть использованы для определения правовой природы публичного размещения акций. При этом, автор приходит к выводу о том, что и сторонники теории договора инвестирования, и сторонники теории договора купли-продажи приводят состоятельные аргументы в пользу своих точек зрения. Однако, ни одна из этих теорий не может быть признана универсальной. В связи с этим автор предлагает использовать теории договора инвестирования или купли-продажи в зависимости от цели, с которой подписчик приобретает выпускаемые акции.
\end{abstract}

Ключевые слова: односторонняя распорядительная сделка, договор инвестирования, подписчик, эмитент ценных бумаг, ценные бумаги, правовая природа, публичное размещение акций, двусторонняя распорядительная сделка, акция, договор купли-продажи.

DOI: 10.7256/1994-1471.2014.2.10302

$\mathrm{O}$ пределение правовой природы публичного размещения акций является одной из не до конца разрешенных проблем в теории права.

В теории права существует целый ряд подходов к тому, каким именно правоотношением является публичное размещение акций:

1. Теория договора инвестирования;

2. Теория односторонней распорядительной сделки;

3. Теория двусторонней распорядительной сделки;

4. Теория договора купли-продажи.

Одной из самых распространенных является теория о том, что публичное размещение акций по своей сути является договором инвестирования между эмитентом и подписчиками на выпускаемые акции (инвесторами).

Так, по мнение А. В. Майфата и М. Н. Колесникова, при размещении акций «эмитент ничего не размещает и не распределяет, он принимает и получает» ${ }^{1}$. Иными словами, во время эмиссии происходит привлечение инвестиций, в

Майфат А. В., Колесников М. Н. Акции: эмиссия, сделки, реестр. Вопросы законодательства и судебная практика. Екатеринбург, 2001, С.33.

результате которого формируется или увеличивается уставный капитал эмитента или происходит изменение правового статуса ценных бумаг, размещенных ранее.

В. Г. Гороватер определяет размещение акций следующим образом: «Размещение акций это возмездная инвестиционная сделка, направленная на возникновение нового объекта права, отличная от договоров купли-продажи или мены, однако допускающая субсидиарное применение режима купли-продажи в отношении обязанностей инвестора по оплате размещаемых акций денежными средствами, либо режима мены - при оплате акций в неденежной форме. Встречным предоставлением со стороны эмитента по данным сделкам являются обязательства по обеспечению надлежащего закрепления и реализации прав из ценной бумаги, возникающей при завершении сторонами исполнения по инвестиционной сделке» ${ }^{2}$.

Если рассмотреть механизм публичного размещения акций с точки зрения сторонников

2 В. Г. Гороватер. Сделки по размещению акций в системе эмиссионных правоотношений / Актуальные проблемы граждаского права. Сборник статей. Под ред. Шилохвост О. Ю. Выпуск 11. Москва 2007. С. 94

(C) Гриб Виталий Викторович

* Аспирант кафедры международного частного права Московского государственного юридического университета имени О.Е. Кутафина (МГЮА)

[vitaly.grib@gmail.com]

123995, Россия, г. Москва, Садовая-Кудринская ул., д. 9. 
теории договора инвестирования, то он будет выглядеть следующим образом.

После акцепта предложения инвестором у эмитента появляется право требования по внесению в свой уставный капитал соответствующего взноса, равного стоимости приобретаемых акций. Необходимо учесть, что эмитент, проводящий публичное размещение акций, «не имеет возможности отказаться от требований инвестора, в случае если таким инвестором выполнены все условия такого предложения» ${ }^{3}$. После же внесения инвестором имущества или денежных средств эмитент не имеет права «отказаться от принятия вносимых инвестором средств либо самостоятельно изменить объем предоставляемых прав, либо по собственной воле отменить принятые решения» ${ }^{4}$.

При этом на стадии размещения «у эмитента возникают обязательства по совершению действий, необходимых для возникновения у конкретного инвестора совокупности прав, составляющих содержание определенного количества размещаемых акций соответствующего выпуска» ${ }^{5}$. К подобным действиям можно отнести, в частности, совершение приходной записи по лицевому счету инвестора, регистрация отчета об итогах выпуска или подача в регистрирующий орган уведомления об итогах выпуска и т.д. Общим же результатом данных действий является возникновение у инвестора права требования в отношении части выпуска акций, приобретаемой инвестором. Следовательно, завершением данного договора будет получение инвестором акций, в качестве встречного обеспечения, за его имущество вложенное в уставный капитал эмитента. При этом, учитывая, что речь идет об акциях, которые являются бездокументарными ценными бумагами, в соответствии с российским законодательством, то завершение оформляется путем включения имени инвестора в реестр держателей акций эмитента.

Сторонники данной теории обращают особое внимание на тот факт, что для того, чтобы акция возникла как объект права, а эмитент приобрел право собственности на взнос инвестора, необходимо наступление ряда юридических фактов.

Во-первых, это заключение между инвестором и эмитентом соответствующего договора

Н.Г. Удальцова Первичное публичное предложение (размещение) ценных бумаг. Правовая природа. М. Берлин. 2012. С. 158

\footnotetext{
4 Н.Г. Удальцова Указ. Соч. С. 159

В.Г. Гороватер Указ. соч. С. 35
}

на приобретение первым акций и служащее основанием для передачи имущества инвестора в пользу эмитента.

Во-вторых, сама по себе передача имущества инвестора эмитенту в качестве оплаты приобретаемых акций, после которой эмитент приобретает право собственности в отношении данного имущества, а инвестор приобретает соответствующие права по отношению к эмитенту.

Однако вышеуказанные авторы отмечают, что сами по себе акции не являются конечной целью инвестора, иначе был бы сделан вывод о том, что размещение акций представляет собой сделку купли-продажи. По мнению сторонников теории инвестиционного договора, целью инвестора являются именно права, которые переходят к ним вместе с выпускаемыми акциями.

С данной теорией сложно согласиться полностью.

Одним из основных аргументов сторонников настоящей теории является тот факт, что акции возникают только после приобретения их инвесторами. Между тем, тот факт, что на момент приобретения акций прав, которые они закрепляют, еще не существует и сам по себе выпуск может быть признан несостоявшимся, не говорит, что публичное размещение акций является договором инвестирования. К примеру, ч. 2 ст. 455 ГК РФ устанавливает, что договор купли-продажи может быть заключен на куплю-продажу товара, имеющегося в наличии у продавца в момент заключения договора, а также товара, который будет создан или приобретен продавцом в будущем. Таким образом, тот факт, что на момент приобретении подписчиком акций, их не существует, не доказывает, что публичное размещение акций может являться только договором инвестирования.

Вторым аргументом сторонников теории инвестиционного договора заключается в том, что инвестора интересует не сама акция, а права по управлению обществом, получению дивидендов и получению части ликвидационной стоимости. Данный аргумент также нельзя считать состоятельным, так как он применим не ко всем подписчикам. Дело в том, что речь идет о публичном размещении акций, а подобное размещение предполагает, что акция после получения ее подписчиком может быть продана еще до первого общего собрания акционеров или получения дивидендов. Таким образом, вполне вероятно, что часть подписчиков может рассматривать акцию не как бумагу, предоставляющую корпоративные права, а как некий актив, который можно реализовать на фондовом рынке. 
Третий аргумент, который сторонники данной теории приводят для ее подтверждения заключается в следующем. Имущество, которое передается инвестором в качестве платы за приобретаемые акции, переходит в собственность эмитента и в дальнейшем используется в обычной хозяйственной или иной деятельности. С данным аргументом также нельзя до конца согласиться. Дело в том, что у эмитента нет прямой обязанности использовать имущество, полученное в результате публичного размещения акций, для каких-то определенных целей. Следовательно, в сущности правовое положение имущества полученного в результате публичного размещения акций или в результате, например, продажи активов эмитента является аналогичным.

Таким образом, нельзя со стопроцентной уверенностью утверждать, что публичное размещение акций является именно договором инвестирования.

Тем не менее необходимо отметить, что и признать полностью несостоятельными аргументы сторонников вышеуказанной теории также нельзя, так как действительно значительная часть подписчиков, если не большинство, приобретает акции именно с целью инвестирования своих средств в уставный капитал компании-эмитента.

Другой теорией правовой природы публичного размещения акций является теория односторонней распределительной сделки. В соответствии с мнением Ю.А. Тарасенко, «действие по внесению вклада можно квалифицировать как распорядительную сделку. В результате этого действия (распорядительной сделки) [подписчик] подтверждает свой статус акционера» ${ }^{6}$. Кроме того, Ю.А. Тарасенко указывает, что особенность данной распорядительной сделки «состоит в том, что, опосредуя процесс распределения акций, она не связана с процессом перехода права собственности» ${ }^{7}$.

Данный подход, на наш взгляд, является ошибочным в силу следующего.

Как указано выше, в соответствии со ст. 2 ФЗ «0 рынке ценных бумаг» размещение эмиссионных ценных бумаг (т.е. в том числе и акций) это отчуждение эмиссионных ценных бумаг эмитентом первым владельцам путем заключения гражданско-правовых сделок. Слово «заключение» в данном определении прямо указывает на двусторонний характер сделок

\footnotetext{
6 Тарасенко Ю.А. О недействительности основания внесения вклада в уставный капитал акционерного общества // Законодательство. 2005. №1. С. 29.

Тарасенко Ю.А. О Природе внесения имущества в уставный капитал при учреждении акционерного общества // Правоведение. 2005. № 3. С. 28.
}

заключаемых между эмитентом и первыми владельцами акций. Таким образом, публичное размещение акций никак не может быть признано односторонней сделкой.

Более того, при публичном размещении акций эмитент размещает публичное предложение по выпускаемым акциям, которое акцептуют или не акцептуют подписчики. Таким образом, будущие акционеры не могут самостоятельно и без учета воли эмитента приобрести размещаемые акции.

Схожее мнение о правовой природе публичного размещения акций высказывает и Н.В. Козлова, с той лишь разницей, что, на ее взгляд, процесс размещения акций представляет собой двусторонние распорядительные сделки. Основанием данных сделок является учредительный договор или договор о совместной деятельности по созданию юридического лица, которые обязывают участников внести свое собственное имущество в уставный капитал юридического лица.

Даннае позиция также, на наш взгляд, не может быть признана верной и обоснованной в силу следующего.

Распорядительная сделка - это «особый вид сделки <...> посредством которой осуществляется перенос определенного имущественного субъективного права (вещного при передаче вещи или обязательственного при уступке права) от одного лица к другому» ${ }^{8}$. Как правило, распорядительную сделку в научной литературе рассматривают как фактическую передачи вещи или права от одного лица другому.

Таким образом, любой договор, связанный с передачей вещей или прав, складывается фактически из двух сделок: обязательственной сделки и распорядительной сделки. Иными словами, любой договор можно разделить на два этапа. На первом этапе стороны согласуют все существенные условия соответствующего договора, а на втором осуществляется непосредственно исполнение договора. При этом если говорить о реальных договорах, то два данных этапа не разделены и фактически совпадают по времени. В консенсуальном договоре, напротив, существует четкое разделение между двумя вышеописанными этапами.

Если вернуться к вопросу о том, можно ли признать публичное размещение акций двусторонней распорядительной сделкой, то у нас сложилось следующее мнение.

При эмиссии ценных бумаг эмитент изначально регистрирует и публикует проспект

8 Бердников В.В. Распорядительная сделка как способ изменения имущественно-правового положения лица / Законодательства. 2002. № 2. С. 15. 
выпускаемых акций, где указывает все условия приобретения размещаемых акций. Иными словами, эмитент размещает публичную оферту на выпускаемые акции. В процессе же размещения подписчиками данная оферта акцептуется, выплачивается стоимость акций и лишь затем происходит запись акционеров в реестр держателей акций или, иными словами, передача прав акционерам на размещаемые акции. Соответственно размещение включает в себя не только распорядительную сделку, но и обязательственную сделку.

Кроме того, вызывает сомнение тот факт, что единственным основанием для размещения акций и передачи их подписчикам является учредительный договор или договор о совместной деятельности.

По нашему мнению, если говорить о размещении акций, то у данного правоотношения можно выделить следующие основания.

Во-первых, это решение общего собрания участников акционерного общества или совета директоров, если данные полномочия были ему переданы. В соответствии с п.2 ст. 28 ФЗ «Об акционерных обществах», а также п. 1 ст. 19 Ф3 «0 рынке ценных бумаг» решение акционеров или совета директоров о выпуске акций является обязательным условием для проведения эмиссии ценных бумаг в принципе и их размещения в частности.

Во-вторых, в соответствии с п. 2 ст. 20 ФЗ «0 рынке ценных бумаг» для регистрации выпуска акций в Банке России эмитент должен представить проспект выпуска акций, где изложены все условия предстоящего размещения акций. При публичном размещении акций данный проспект является общедоступным и по сути является офертой, которую в итоге акцептуют подписчики. Таким образом, проспект выпуска акций также является основанием размещения акций.

И наконец, в-третьих, само по себе размещение складывается из отдельных договоров о приобретении акций заключаемых между эмитентом и подписчиками. Таким образом, данные договоры также можно признать основанием размещения акций.

Следовательно, публичное размещение акций является сложным правоотношением, выходящим за рамки распорядительной сделки и имеющее множественное основание.

И, наконец, четвертой теорией является теория договора купли-продажи. К сторонникам данной теории можно отнести Р.С. Бевзенко, который утверждает, что «Акционерное общество приобретает имущество, вносимое в уставный капитал, по двустороннему возмездному договору - договору подписки на акции, заключаемому между акционерным обществом и лицом, желающим стать его акционером» ${ }^{9}$. Схожие взгляды отстаивает и В.Ю. Бакшинскас: «Правовым основанием размещения акций общества и их оплаты, в том числе и при учреждении общества, является отдельный (отдельные) договор (договоры) купли-продажи, заключаемый при проведении подписки на акции» ${ }^{10}$.

При этом необходимо отметить, что нельзя воспринимать эмитента акций в качестве первого собственника акций. Дело в том, что в соответствии с Ф3 «0 рынке ценных бумаг» акции как таковые не существуют как объекты гражданского права до момента их размещения, т.е. момента передачи акций от эмитента подписчику.

Противники данной теории, как правило, вменяют данное обстоятельство в качестве основного аргумента против того, чтобы признать размещение акций по своей правовой природе является сделкой-купли продажи. Выше мы уже указывали, что для договора купли-продажи можно заключить и на вещь, которая на момент заключения договора не существует. На данный аргумент можно возразить, что даже в случае когда товар создается специально для покупателя, в период времени до его передачи покупателю, товар существует в качестве объекта гражданских прав. Между тем необходимо обратить внимание на характер самой акции. В соответствии со ст. 2 ФЗ «0 рынке ценных бумаг» акция является именной ценной бумагой. Кроме того, в соответствии со ст. 16 Ф3 «0 рынке ценных бумаг» именные ценные бумаги могут издаваться только в форме бездокументарных ценных бумаг. Следовательно, акции могут быть только бездокументарными ценными бумагами. Таким образом, данные ценные бумаги существуют только в форме записей в реестре держателей акций. Поэтому тот факт, что акции не существуют до передачи их покупателю, связан исключительно с их бездокументарной формой и никак не может противоречить тому, что размещение акций является сделкой купли-продажи. Следовательно, данный аргумент противников данной теории является несостоятельным.

Таким образом, как мы и обозначили в начале настоящей статьи, в теории права существует четыре теории правовой природы публичного размещения акций. При этом на

\footnotetext{
9 Бевзенко Р.С. Истребование имущества, внесенного в уставный капитал юридического лица // Законодательство. 2004. № 12. С. 21.

10 Бакшинскас В.Ю. Формирование уставного капитала в процессе учреждения акционерного общества (правовые вопросы) // Законодательство. 1998. № 1. С. 35.
} 
наш взгляд, состоятельные аргументы есть лишь у сторонников двух теорий: договора инвестирования и договора купли-продажи. На наш взгляд, невозможно отдать предпочтение только одной из данных теорий.

По нашему мнению, ключевой причиной того, что невозможно полностью определиться с тем, какая именно из теорий полностью отражает правовую природу публичного размещения акций, является тот факт, что подписчики покупают акции либо в целях инвестирования, либо в целях последующей перепродажи. В связи с этим, нам кажется разумным сделать вывод о том, что обе теории являются состоятельными в различных случаях.

Когда подписчик приобретает размещаемые акции с целью дальнейшего извлечения прибыли в виде получения дивидендов, а также с целью управления компанией-эмитентом можно сделать вывод о том, что в данном случае публичное размещение акций представляет собой договор инвестирования.

С другой стороны, если подписчик приобретает эмитируемые акции с целью дальнейшей перепродажи, то очевидно, что в данном случае публичное размещение акций представляет собой договор купли-продажи.

\section{Библиография}

1. Майфат А. В., Колесников М. Н. Акции: эмиссия, сделки, реестр. Вопросы законодательства и судебная практика. - Екатеринбург, 2001. - С.33.

2. В. Г. Гороватер. Сделки по размещению акций в системе эмиссионных правоотношений // Актуальные проблемы гражданского права. Сборник статей. Под ред. Шилохвост О. Ю. Выпуск 11. Москва 2007. С. 35.

3. В. Г. Гороватер. Сделки по размещению акций в системе эмиссионных правоотношений // Актуальные проблемы гражданского права. Сборник статей. Под ред. Шилохвост О. Ю. Выпуск 11. Москва 2007. С. 94.

4. Н. Г. Удальцова. Первичное публичное предложение (размещение) ценных бумаг. Правовая природа. М. - Берлин. 2012. С. 158-159.

5. Тарасенко Ю. А. О недействительности основания внесения вклада в уставный капитал акционерного общества // Законодательство. 2005. №1. С.29.

6. Тарасенко Ю. А. О природе внесения имущества в уставный капитал при учреждении акционерного общества // Правоведение. 2005. № 3. С. 28.

7. Бердников В. В. Распорядительная сделка как способ изменения имущественно-правового положения лица // Законодательство. 2002. № 2. С. 15.

8. БевзенкоР.С.Истребование имущества, внесенноговуставныйкапитал юридическоголица // Законодательство. 2004. № 12. С. 21.

9. Бакшинскас В. Ю. Формирование уставного капитала в процессе учреждения акционерного общества (правовые вопросы) // Законодательство. 1998. № 1. С. 35.

10. Ласк Г. Гражданское право США [Текст] : (Право торгового оборота) / Сокр. пер. с англ. Ю. Э. Милитаревой и В. А. Дозорцева ; Под ред. и с вступ. статьей д-ра юрид. наук проф. Е. А. Флейшицю М. 1961.

11. Юлдашбаева Л. Р. Правовое регулирование оборота эмиссионных ценных бумаг (акций, облигаций). М. 1999.

12. Редькин И. В. Меры гражданско-правовой охраны прав участников отношений в сфере рынка ценных бумаг. М. 1997.

13. Агарков М. М. Основы банковского права. Учение о ценных бумагах. М. 1994.

14. Шершеневич Г. Ф. Учебник торгового права. М. 1994.

\section{References}

1. Maifat A. V., Kolesnikov M. N. Aktsii: emissiya, sdelki, reestr. Voprosy zakonodatel'stva i sudebnaya praktika. - Ekaterinburg, 2001. - S.33.

2. V. G. Gorovater. Sdelki po razmeshcheniyu aktsii v sisteme emissionnykh pravootnoshenii // Aktual'nye problemy grazhdanskogo prava. Sbornik statei. Pod red. Shilokhvost O. Yu. Vypusk 11. Moskva 2007. S. 35.

3. V. G. Gorovater. Sdelki po razmeshcheniyu aktsii v sisteme emissionnykh pravootnoshenii // Aktual'nye problemy grazhdanskogo prava. Sbornik statei. Pod red. Shilokhvost O. Yu. Vypusk 11. Moskva 2007. S. 94.

4. N. G. Udal'tsova. Pervichnoe publichnoe predlozhenie (razmeshchenie) tsennykh bumag. Pravovaya priroda. M. - Berlin. 2012. S. 158-159. 
5. Tarasenko Yu. A. O nedeistvitel'nosti osnovaniya vneseniya vklada v ustavnyi kapital aktsionernogo obshchestva // Zakonodatel'stvo. 2005. №1. S.29.

6. Tarasenko Yu. A.O prirode vneseniya imushchestva v ustavnyi kapital pri uchrezhdenii aktsionernogo obshchestva // Pravovedenie. 2005. № 3. S. 28.

7. Berdnikov V. V. Rasporyaditel'naya sdelka kak sposob izmeneniya imushchestvenno-pravovogo polozheniya litsa // Zakonodatel'stvo. 2002. № 2. S. 15.

8. Bevzenko R. S. Istrebovanie imushchestva, vnesennogo v ustavnyi kapital yuridicheskogo litsa // Zakonodatel'stvo. 2004. № 12. S. 21.

9. Bakshinskas V. Yu. Formirovanie ustavnogo kapitala v protsesse uchrezhdeniya aktsionernogo obshchestva (pravovye voprosy) // Zakonodatel'stvo. 1998. № 1. S. 35.

10. Lask G. Grazhdanskoe pravo SShA [Tekst] : (Pravo torgovogo oborota) / Sokr. per. s angl. Yu. E. Militarevoi i V. A. Dozortseva ; Pod red. i s vstup. stat'ei d-ra yurid. nauk prof. E. A. Fleishitsyu M. 1961.

11. Yuldashbaeva L. R. Pravovoe regulirovanie oborota emissionnykh tsennykh bumag (aktsii, obligatsii). M. 1999.

12. Red'kin I. V. Mery grazhdansko-pravovoi okhrany prav uchastnikov otnoshenii v sfere rynka tsennykh bumag. M. 1997.

13. Agarkov M. M. Osnovy bankovskogo prava. Uchenie o tsennykh bumagakh. M. 1994

14. Shershenevich G. F. Uchebnik torgovogo prava. M. 1994.

Материал поступил в редакцию 21 ноября 2013 г. 